\title{
Efecto de la inclusión de una fuente \\ de fibra dietaria sobre la degradación \\ lipídica y proteica de un producto \\ cárnico tipo hamburguesa
}

\author{
Effect of adition of plantain dietary \\ fiber on lipid and protein \\ spoilage in a hamburger-like \\ meat product
}

\begin{abstract}
A source of dietary fiber obtained from plantain peel (Musa AAB) was characterized in terms of dietary fiber, total phenols and antioxidant capacity in order to generate proposal for use of the byproducts of plantain agribusiness. Thereafter, the effect of the inclusion of the source of dietary fiber was evaluated at levels of $0 \mathrm{~g}, 5.5 \mathrm{~g}$, y $6.5 \mathrm{~g}$ (treatment) of adding source of dietary fiber $1100 \mathrm{~g}$ in a hamburger-type meat product during a time period of 28 days (with sampling on days 0, 7, 14, 21 and 28) on lipid and protein spoilage in terms of malonaldehyde production per gram of meat product and volatile nitrogenous bases per $100 \mathrm{~g}$ of meat product. Treatments including dietary fiber had no significant effect on lipid degradation ( $p>0.05)$ while protein degradation had statistically significant differences $(p<0.05)$, volatile nitrogenous bases values were lower on treatments with 5.5, y $6.5 \mathrm{~g}$ of adding source of dietary fiber $/ 100 \mathrm{~g}$ in a hamburger. It is concluded that the high fiber source obtained from dietary plantain peels by applied process may be used to increase hamburger's dietary fiber level and to prevent protein degradation.

Key words: dietary fiber, antioxidant capacity, plantain peel,

spoilage lipid, spoilage protein.
\end{abstract}

\section{INTRODUCCIÓN}

Los polifenoles son sustancias ampliamente distribuidas en el reino vegetal que se sintetizan como metabolitos secundarios, más específicamente a través de la vía metabólica de shikamato [1], teniendo todos en su estructura uno o varios anillos aromáticos con al menos un grupo hidroxilo el cual es fundamental para el mecanismo antioxidante que generan, $y$ por el cual actúan los polifenoles ya que este grupo hidroxilo tiene la capacidad de donar un electrón a un radical libre para estabilizarlo, lo cual da lugar a una quinona que es capaz de permanecer estable con un electrón desapareado [2].

La cáscara de plátano es reportada en la literatura como un subproducto que posee un alto contenido de moléculas con capacidad antioxidante las cuales corresponden principalmente a polifenoles según los estudios de Someya, Yoshiki y Okubo [3] y González, Lobo y González [4] quienes reportan que la cáscara de los frutos del genero Musa posee
Miguel Ángel Alarcón G. (1)

Jairo Humberto López V. (1)

Diego Alonso Restrepo M. (2)

(1) Instituto de Ciencia y Tecnología de Alimentos (ICTA), Sección Carnes, Universidad Nacional de Colombia Sede Bogotá. Colombia. (2) Departamento de Ingeniería Agrícola y de Alimentos, Facultad de Ciencias Agrarias, Universidad Nacional de Colombia Sede Medellín, Colombia.

Dirigir la correspondencia a: Profesor Miguel Angel Alarcón G.
Instituto de Ciencia y Tecnología de Alimentos - ICTA Ciudad Universitaria

Universidad Nacional de Colombia, Sede Bogotá Carrera 30, No $45-03$ Teléfono: 3165000 ext: 19216 E-mail: maalarcong@unal.edu.co

Este trabajo fue recibido el 2 de Julio de 2013 y aceptado para ser publicado el 3 de Noviembre de 2013.

907 mg equivalentes a ácido gálico/100 g de cáscara seca y entre 110 y 2800 mg equivalentes a ácido gálico/100 g de cáscara seca respectivamente (dependiendo del solvente usado para la extracción de los polifenoles al que se someta la cáscara del fruto). Por lo anterior también se le atribuyen valores de capacidad antioxidante para extractos etanólicos entre 4,5 y 5,9 mg equivalentes a trolox/g de cáscara seca para la técnica que usa el radical DPPH y una capacidad antioxidante para extractos etanólicos de 3,5 a 4,9 mg equivalentes a trolox/g de muestra seca para la técnica que usa el radical ABTS [4].

Otras moléculas reportadas, pertenecientes al grupo de los fenoles y halladas en este tipo de subproductos son la dopamina y la L-dopa, ambas influyen aumentando los valores de capacidad antioxidante ante la presencia de radicales libres [4]. Otro de los componentes de importancia hallados en las cáscaras de plátanos y bananos, es la fibra dietaria, la cual 
según los datos reportados por Happi et al. [5] puede oscilar entre $32,9 \%$ y $49,7 \%$ en base seca dependiendo del estado de maduración (el cual se toma en cuenta dependiendo de la coloración de la cáscara que va de verde en su estado inmaduro a amarillo en su estado óptimo de maduración para consumo) y de la variedad de plátano.

Los objetivos de este estudio fueron obtener una fuente de fibra dietaria a partir del subproducto cáscara de plátano con el fin de caracterizarla en términos de fibra dietaria total, fibra dietaria insoluble, fibra dietaria soluble, capacidad antioxidante y nivel de fenoles totales; de la misma manera evaluar el efecto de la inclusión de esta fuente de fibra sobre la degradación lipídica y proteica en un producto cárnico tipo hamburguesa y adicionalmente poder rotular el producto cárnico tipo hamburguesa con el descriptor "buena fuente de fibra" al incluir la fuente de fibra dietaria nivel que permitió garantizar que el producto cárnico contara con 2,5 g de fibra dietaria/porción equivalente al 10\% del valor de referencia para el requerimiento diario de fibra dietaria total de un individuo de la población colombiana (25 g/día) [6].

\section{MATERIALES Y MÉTODOS}

Obtención de una fuente de fibra a partir de cáscara de plátano

Se utilizó la metodología propuesta por Buitrago [7] para obtener una fuente de fibra dietaria. Se procesó un lote de plátano verde (Musa $A A B$ ) de no más de un día de cosechado de la variedad Hartón Dominico proveniente de la zona de los departamentos de Armenia y Quindío, Colombia. En primer lugar se hizo la recepción del lote de plátano verde, se procedió a hacer una selección de los frutos que poseían ningún o muy bajo grado de deterioro a través de inspección visual directa para proceder con el pelado a mano de los frutos; las cáscaras obtenidas fueron sumergidas inmediatamente después del pelado en una solución de eritorbato de sodio (1\%) y Ácido cítrico $(0,5 \%)$ con el objetivo de evitar el pardeamiento enzimático $[8,9]$. Posteriormente se realizaron lavados consecutivos de las cáscaras utilizando tres litros de solución de eritorbato de sodio y ácido cítrico por cada kilogramo de cáscara con el fin de eliminar posibles restos de tierra u otro tipo de contaminante proveniente de la zona de cosecha y poder proceder con la molienda en húmedo con un molino de martillos FitzMill, Illinois, EE.UU. modelo Comminutor, en el cual se hicieron dos moliendas consecutivas con diferentes tamaños de criba (criba 1,5 cm y $1 \mathrm{~mm}$ para la primera y segunda molienda respectivamente), obteniendo un tamaño de partícula que permitió hacer posteriormente un proceso de arrastre de almidón con lavados sucesivos del material previamente molido utilizando un filtro de tela. Una vez realizado el filtrado se procedió al secado del material resultante, a una temperatura de $60^{\circ} \mathrm{C}$, hasta que éste alcanzó una humedad aproximada de 5\% en un secador ThermoScientific, Alemania y finalmente se sometió el material a una molienda en seco en un molino de martillos Raymond SCREE Mill, Illinois, EE.UU., con una criba a través de la cual se obtuvo un tamaño de partícula máximo de 595 micras.

\section{Determinación de fibra dietaria total soluble e insoluble}

La fuente de fibra dietaria obtenida de la cáscara de plátano de la variedad Hartón Dominico fue caracterizada en términos de fibra dietaria total (FDT), determinada por el método enzimático- gravimétrico 985,29 de la AOAC [10], fibra dietaria insoluble (FDI), determinada por el método enzimático-gravimétrico, buffer de fosfato 991,42 de la AOAC [10] y fibra dietaria soluble (FDS), determinada por cálculo de la diferencia (FDS = FDT-FDI).

\section{Determinación del contenido de fenoles totales} y la capacidad antioxidante

Para la determinación del contenido de fenoles totales y de la capacidad antioxidante se procedió a elaborar extractos etanólicos de la fuente de fibra dietaria para lo cual se pesaron 1,5 g de muestra en vasos de precipitado de $100 \mathrm{~mL}$, se adicionaron $30 \mathrm{~mL}$ de etanol al 96\% de pureza por cada gramo de muestra pesada, posteriormente se colocó en el interior de cada vaso una barra magnética mediana y se cubrió el vaso por completo con una lámina de papel aluminio. Los vasos de precipitado fueron llevados a una plancha de agitación donde permanecieron en agitación por un periodo de 24 horas. Una vez transcurrido el tiempo de agitación se transvasó el contenido de los vasos a balones aforados de 100 $\mathrm{mL}$ y los remanentes insolubles fueron removidos mediante la utilización de papel filtro; posteriormente se completó el volumen de los balones con etanol al 96\%. El almacenamiento de los extractos se hizo a una temperatura de $-20^{\circ} \mathrm{C}$ hasta su análisis, momento en el cual se dejó descongelar hasta alcanzar temperatura ambiente; todas las mediciones fueron realizadas con el espectrofotómetro ThermoScientific GENESYS 10, Wisconsin, EE. UU.

Medición de fenoles totales

Para la medición de los fenoles totales se utilizó el método de Folin Ciocalteu reportado por Stratil, Klejdus y Kubán [11], método que se basa en la reducción del complejo fosfowolframato-fosfomolibdato al entrar en contacto con fenoles lo cual ocasiona un aumento de la absorbancia medida a $765 \mathrm{~nm}$.

\section{Medición de la capacidad antioxidante por el método ABTS•+}

Se siguió la metodología reportada por Re et al. [12] para la medición de la capacidad antioxidante, metodología que se basa en la reducción de la absorbancia medida a $734 \mathrm{~nm}$ del radical catión ABTS al entrar en contacto con antioxidantes.

\section{Medición de la capacidad antioxidante por el método DPPH}

Se siguió la metodología reportada por González, Lobo y González [4] para la medición de la capacidad antioxidante, metodología que se basa en la reducción de la absorbancia medida a $515 \mathrm{~nm}$ del radical DPPH al entrar en contacto con antioxidantes.

\section{Medición de la capacidad antioxidante por el método FRAP}

Se siguió la metodología reportada por Benzie y Strain [13] para la medición de la capacidad antioxidante, metodología que se basa en un aumento de la absorbancia medida a $593 \mathrm{~nm}$ al entrar en contacto el complejo $\mathrm{Fe}^{+3}-2,4,6$ - Tri (2 -pyridyl) - 1,3,5 - triazine (FRAP: $\mathrm{Fe}^{+3}-\mathrm{TPTZ}$ ) con antioxidantes y producir mediante la reducción del hierro el complejo $\mathrm{Fe}^{+2}-2,4,6$ - Tri (2 -pyridyl) - 1,3,5 - triazine (Fe' $\left.{ }^{+2}-\mathrm{TPTZ}\right)$, lo cual genera una coloración azul que aumenta o disminuye su intensidad dependiendo de la capacidad antioxidante del compuesto evaluado. 
Inclusión de la fuente de fibra dietaria en la hamburguesa

Se siguió un procedimiento industrial estandarizado para la fabricación de la hamburguesa de la categoría estándar según la NTC 1325 [14] (proteína 10\% mínimo, grasa $28 \%$ máximo, humedad más grasa $90 \%$ máximo, almidón $10 \%$ máximo y proteína no cárnica $10 \%$ máximo). La fuente de fibra dietaria obtenida de cáscara de plátano fue incluida en la formulación a un nivel de 0\%, 5,5\% y 6,5\% durante un proceso de picado fino en un "cutter" Javar, Colombia, donde se utilizaron todos los aditivos y el $80 \%$ de los ingredientes cárnicos con el objetivo de crear una emulsión cárnica que permitiera la incorporación de la fuente de fibra dietaria y posteriormente la pasta cárnica resultante fue mezclada con el $20 \%$ restante de los ingredientes cárnicos molidos para poder dar al producto la apariencia de hamburguesa con partículas groseras. Posteriormente a la etapa de mezclado de los ingredientes de la hamburguesa, se procedió a embutir el producto cárnico en una funda de poliamida el cual una vez embutido se sometió al primer tratamiento térmico que consistió en la inmersión del embutido con funda de poliamida en agua a $75^{\circ} \mathrm{C}$ hasta que alcanzó una temperatura interna igualmente de $72^{\circ} \mathrm{C}$ (según especificaciones NTC 1325 [14]) por un lapso de tiempo de 5 minutos; posteriormente el producto cocido se dejó atemperar para poder almacenarlo a temperatura de refrigeración $\left(3^{\circ} \mathrm{C} \pm 1\right)$ y finalmente después de refrigerado se procedió al tajado con el fin obtener hamburguesas de $110 \mathrm{~g}$ a las cuales se les aplicó un segundo tratamiento térmico en el cual se sometieron las hamburguesas obtenidas del tajado a $170^{\circ} \mathrm{C}$ durante 7,5 minutos por cada lado en una plancha caliente. Los lotes experimentales tuvieron un peso de 14 $\mathrm{kg}$ con 3 repeticiones en total por tratamiento, tanto para el tratamiento testigo como para los tratamientos que incluyen $5,5 \%$ y $6,5 \%$ de la fuente de fibra y las unidades experimentales tuvieron un peso de $100 \pm 5$ gramos cada una al finalizar el segundo tratamiento térmico. Una vez terminada la elaboración de los productos cárnicos tipo hamburguesa, se realizó un análisis proximal de los productos cárnicos sin adición de la fuente de fibra dietaria (tratamiento control con $0 \mathrm{~g}$ de fuente de fibra dietaria/100 g de hamburguesa) y con adición de la fuente de fibra dietaria (tratamientos con 5,5 g de fuente de fibra dietaria/100 g de hamburguesa y $6,5 \mathrm{~g}$ de fuente de fibra dietaria/100 g de hamburguesa) en términos de Humedad (AOAC [15] método 950,46), proteína cruda (AOAC [15] método 935,11), extracto etéreo (AOAC [15] método 920,39), cenizas (AOAC [15] método 923,03) y fibra dietaria total AOAC [10] método $985,29)$. Lo anterior con el fin de verificar que los productos cárnicos poseían una composición química acorde a la formulación del producto. Posteriormente en el producto cárnico terminado se midieron las variables respuesta $\mu \mathrm{g}$ de malonaldehído/g de producto cárnico con inclusión de fuente de fibra dietaria y $\mathrm{mg}$ de bases nitrogenadas volátiles/100 g de producto cárnico (hamburguesa) con inclusión de fuente de fibra dietaria durante el tiempo de desarrollo del componente experimental que duró 28 días con muestreos los días 0, 7, 14, 21 y 28. Durante los 28 días de estudio los productos permanecieron almacenados bajo condiciones de refrigeración $\left(3^{\circ} \mathrm{C} \pm 1\right)$ debidamente identificados en bandejas de icopor $(21 \mathrm{~cm} \times 15 \mathrm{~cm})$ envueltas en plástico vinipel (Material P.V.C transparente, brillante, auto adherente, no toxico e inholoro) que contenían tres unidades experimentales cada una.

\section{DISEÑO EXPERIMENTAL}

Para el análisis estadístico de los datos se aplicó un modelo de medidas repetidas en el tiempo para el análisis de varianza en donde se relacionan fuentes de variación representadas por los diferentes niveles de inclusión de la fuente de fibra obtenida de cáscara de plátano en una fórmula estándar abierta de hamburguesa y el comportamiento de las variables respuesta a través del tiempo, para lo cual se estableció un tratamiento control ( $0 \%$ de inclusión de la fuente de fibra dietaria) y dos tratamientos con diferentes niveles de inclusión (5,5\% y 6,5\%) de la fuente de fibra dietaria obtenida a partir de cáscara de plátano, cada tratamiento con tres repeticiones. Adicional a esto se aplicaron pruebas de significancia de Tukey. Se usó el paquete estadístico SAS 9.2 Institute Inc Cary, NC, EE.UU.

Modelo: $Y_{i j k}=\mu+e_{i}\left(T_{j}\right)+T_{j}+\beta_{k}+(T \beta)+\varepsilon_{i j k}$ En donde:

$j=1,2,3$ (tratamientos $0 \%$ de inclusión, 5,5\% de inclusión y $6,5 \%$ de inclusión respectivamente)

$i=1,2,3$ (repeticiones)

$y_{i j k}=$ Respuesta en la i-ésima repetición del j-ésimo tratamiento en el k-ésimo tiempo

$\mu=$ promedio poblacional de las variables respuesta

$T=$ efecto del $j$-ésimo tratamiento sobre las variables respuesta

$\beta=$ efecto del k-ésimo tiempo sobre las variables respuesta

$\varepsilon_{i j k}=$ Error experimental en la i-ésima repetición del j-ésimo tratamiento en el k-ésimo tiempo.

\section{RESULTADOS Y DISCUSIÓN}

Los resultados de las mediciones de fibra dietaria muestran que la fuente de fibra dietaria obtenida a partir de cáscara de plátano posee valores de a 46,79 g/100g de fuente de fibra dietaria, 45,12 $\mathrm{g} / 100 \mathrm{~g}$ de fuente de fibra dietaria $y$ $1,68 \mathrm{~g} / 100 \mathrm{~g}$ de fuente de fibra dietaria para FDT, FDI y FDS respectivamente. El valor de FDT resulta ser superior al de otros estudios donde se reporta un nivel de FDT de 32,9 $\mathrm{g} / 100 \mathrm{~g}$ de fuente de fibra dietaria y 35,9 g/100g de fuente de fibra dietaria en híbridos $A A B$ del genero Musa de las variedades French Clair y Big Ebanga respectivamente. Estos valores corresponden a los frutos en un estado de maduración prematuro donde el color de la cáscara es totalmente verde [5]. De la misma manera el valor de FDT obtenido en esta investigación es superior al ser comparado con el de otras fuentes de fibra dietaria reportadas como la de fibra de naranja a la que se le atribuye un nivel de FDT de 36,9 g/100g de fuente de fibra dietaria [16], el salvado de arroz con nivel de FDT de 27,04 g/100g de fuente de fibra dietaria según Abdul y Luan [17] y fibra de mango concentrada con un nivel de FDT reportado por Vergara et al. [18] de 28,05 $\mathrm{g} / 100 \mathrm{~g}$ de fuente de fibra dietaria. Otros recursos como el del salvado de trigo que presenta valores de FDT de 44,46 g/100g de fuente de fibra dietaria [19] se encuentra en un nivel más próximo. En otros estudios, se pueden encontrar recursos con mayores niveles de FDT como la cáscara de limón, la cual puede llegar a presentar valores de FDT que oscilan entre 60,1 g/100g de fuente de fibra dietaria y 68,3 g/100g de fuente de fibra dietaria [20]. Por lo anterior se puede considerar que la fuente de fibra dietaria obtenida a partir de cáscara de plátano posee niveles de fibra dietaria altos, lo que sugiere que existe un gran potencial para su aplicación como ingrediente que aportaría una fracción fibrosa en cantidades significativas en productos procesados con el objetivo de lograr que una inclusión mínima de fibra dietaria 
pueda beneficiar al consumidor con los efectos fisiológicos reportados en la literatura científica [21, 22].

En cuanto a los valores de capacidad antioxidante medidos por los métodos ABTS ${ }^{*}, \mathrm{DPPH}^{\bullet}$ y FRAP (tabla 1) se pudo observar que a pesar de que el pardeamiento enzimático estuvo presente durante la obtención de la fuente de fibra dietaria, todavía existían componentes con capacidad antioxidante, posiblemente fenoles no oxidados y rastros del eritorbato de sodio utilizado durante el proceso de obtención de la fuente de fibra dietaria. Estos valores obtenidos, comparados con algunos reportes en cáscara de frutos del genero Musa, muestran una menor capacidad antioxidante ya que la literatura reporta, por ejemplo, valores de capacidad antioxidante medida por el método $\mathrm{DPPH}^{\bullet}$ para extractos etanólicos entre 4,5 y 5,9 mg equivalentes a trolox/g de cáscara seca [4] los cuales resultan ser más mayores a lo obtenido en la presente investigación con 1,98 mg equivalentes a trolox/g de fuente de fibra dietaria. De la misma manera, en la literatura se hallan valores superiores con respecto a lo mostrado en la tabla 1 en términos de capacidad antioxidante medida por el método $\mathrm{DPPH}^{\bullet}$ como lo reportan Sulaiman et al. [23] quienes presentan para los híbridos $A A B$ del genero Musa valores de extractos acuosos de hasta 2,42 y 2,92 mg equivalentes a trolox/g cáscara seca (para las variedades Rastali y Nangka respectivamente) y valores de extractos metanólicos de hasta 3,1 y 3,36 mg equivalentes a trolox/g cáscara seca (para las variedades Rastali y Nangka respectivamente). Una situación diferente se presenta para los valores de capacidad antioxidante en extractos etanólicos reportados para el métodos $\mathrm{ABTS}^{\bullet+}$ donde las cáscaras del genero Musa presentan valores de 3,5 a 4,9 mg equivalentes a trolox/g de cáscara seca [4] y para extractos metanólicos de 5,67 mg equivalentes a trolox/g de cáscara seca [24], mientras que el valor obtenido de capacidad antioxidante para extractos etanólicos en este estudio fue de 133,18 mg equivalentes a trolox/g de fuente de fibra dietaria; a pesar de lo anterior González, Lobo y González [4] sostienen que los compuestos presentes en la cáscara de plátano poseen altos valores de capacidad antioxidante en presencia de los radicales $\mathrm{DPPH}^{\bullet}$ y $\mathrm{ABTS}^{*+}$ según su investigación. En cuanto a los valores de capacidad antioxidante obtenidos a través del método FRAP $(8,59 \mathrm{mg}$ equivalentes a trolox/g cáscara seca), éstos también resultan ser menores a los reportados por Sulaiman et al. [23] quienes muestran en su investigación que la capacidad antioxidante de extractos acuosos presenta valores de 16,36 y 13,63 mg equivalentes a trolox/g cáscara seca para las variedades Rastali y Nangka respectivamente mientras los extractos metanólicos presentan valores de 6,45 y 10,32 mg equivalentes a trolox/g cáscara seca para las variedades Rastali y Nangka respectivamente, siendo solamente el valor de capacidad antioxidante del extracto metanólico de la variedad Rastali inferior al valor mostrado en la tabla 1 para capacidad antioxidante de extracto etanólico medida por el método FRAP. Por lo anterior, una vez hecha la comparación de resultados del presente estudio con la literatura, la fuente de fibra dietaria obtenida a partir de cáscara de plátano presenta una capacidad antioxidante alta con respecto a algunos valores reportados [4, 24].

En cuanto al contenido de fenoles totales la prueba de Folin Ciocalteu, aplicada a la fuente de fibra dietaria obtenida a partir de cáscara de plátano, mostró que los fenoles presentes corresponden a $4 \mathrm{mg}$ equivalentes a ácido gálico/g de fuente de fibra dietaria, el cual es mayor a lo reportado en cáscara de frutas del género Musa según el estudio de González, Lobo y González [4] quienes en su estudio muestran valores que se encuentran entre 2,3 y 3,5 mg equivalentes a ácido gálico/g de cáscara seca. Babbar et al. [24] reportan valores de 3,8 mg equivalentes a ácido gálico/g de cáscara seca, similares a lo obtenido en esta investigación, en un estudio donde se caracterizaron en términos de fenoles totales y capacidad antioxidante, seis residuos de las frutas más importantes del estado de Punjab, India, entre las cuales se encontraba la cáscara de especies frutales del género Musa. La anterior diferencia de valores entre las mediciones realizadas en los diferentes estudios (incluyendo éste) podría deberse a condiciones particulares de cada proceso para la obtención de extractos ricos en compuestos con capacidad antioxidante, ya que las condiciones de proceso pueden afectar significativamente el nivel de éstos [25]. Para este caso en particular debido a que la fuente de fibra fue usada para su inclusión en un producto cárnico tipo hamburguesa, la cáscara de plátano fue sometida a un proceso que involucró exposición al oxígeno ambiental después de romper la estructura a través de la etapa de molido (proceso de obtención) y exposición a temperaturas de hasta $60^{\circ} \mathrm{C}$ en la etapa de secado, lo cual en ensayos preliminares afectó notoriamente los fenoles presentes en la cáscara generando un alto grado de pardeamiento enzimático en el cual participa activamente por la polifenoloxidasa; por tal motivo fue necesaria la inclusión de eritorbato de sodio (al 1\%) y ácido cítrico (al 0,5\%) con el fin de generar un efecto protector sobre los polifenoles presentes. A pesar de lo anterior se evidenció pardeamiento enzimático, pero en un menor grado, debido a la presencia de eritorbato de sodio y el ácido cítrico, lo que permitió conservar una fracción de los polifenoles iniciales, hecho que podría explicar porque el valor de fenoles totales obtenido en el presente estudio es superior al de la literatura citada.

El monitoreo de la peroxidación lipídica que se produce en cualquier producto cárnico durante su almacenamiento mostró para esta investigación que los niveles de malonalde-

TABLA 1

Caracterización de la fuente de fibra dietaria en términos de fracciones de fibra dietaria, capacidad antioxidante y contenido de fenoles totales.

Componente

Capacidad antioxidante ABTS*+

Capacidad antioxidante DPPH

Capacidad antioxidante FRAP
Concentración

$133,18 \mathrm{mg}$ equivalentes a trolox/g de fuente de fibra

$1,98 \mathrm{mg}$ equivalentes a trolox/g de fuente de fibra

$8,59 \mathrm{mg}$ equivalentes a trolox/g de fuente de fibra 
hído variaron significativamente $(p<0,05)$ a través del tiempo, según los resultados obtenidos de cada tratamiento (tabla 2), indicando que a medida que transcurrió el tiempo de almacenamiento también lo hicieron los valores de malonaldehído. Adicional a lo anterior, aunque los resultados muestran un aumento de los valores de malonaldehído durante el transcurso del estudio, se puede observar que a partir del día 14 en los siguientes días de muestreo los valores de malonaldehído no presentaron diferencia estadísticamente significativa $(P>0,05)$ para los tres tratamientos a excepción del valor registrado para el tratamiento con Inclusión de 6,5 g fuente de fibra dietaria/100 g de hamburguesa en el día de muestreo 28 donde el aumento de los valores de malonaldehído vuelve a ser significativo estadísticamente $(p<0,05)$ con respecto al valor reportado en el día de muestreo inmediatamente anterior. Lo anterior presenta el mismo comportamiento en términos de producción de malonaldehído a través del tiempo con lo reportado por Fernández et al. [26] en un estudio donde se utilizó una fuente de fibra proveniente de frutas cítricas en un embutido tipo boloña a niveles de inclusión de 0,0,0,5, $1,0,1,5$ y 2,0 g/100g de embutido (tratamientos). Este estudio reporta que durante el almacenamiento del producto cárnico también se presentó un aumento significativo de los valores de malonaldehído los cuales aumentaron de alrededor de $4 \mu \mathrm{g} / \mathrm{g}$ de muestra al comienzo del estudio para todos los tratamientos a valores de alrededor de $7 \mu \mathrm{g} / \mathrm{g}$ al finalizar el estudio para todos los tratamientos. De la misma manera en otros productos cárnicos con inclusión de fuentes de fibra dietaria provenientes de subproductos agroindustriales se reporta un aumento en los niveles de malonaldehído durante el período de almacenamiento, como es el caso de un estudio donde se tomaron hamburguesas crudas y cocidas de pollo a las cuales durante su fabricación les fue incluida en su formulación una adición de fibra dietaria de uva obtenida a partir de los residuos de la industria vinícola española a niveles de $0,0,0,5,1,0,1,5$ y $2,0 \mathrm{~g} / 100 \mathrm{~g}$ de hamburguesa y adicionalmente se mantuvieron en refrigeración por 13 días a $4^{\circ} \mathrm{C}$. Estas hamburguesas fueron muestreadas en los días 0, 3, 5 y 13 mostrando que los niveles de malonaldehído aumentaron significativamente a través del tiempo sin importar si los productos cárnicos fueron sometidos a cocción o no [27]. En cuanto a la comparación entre tratamientos, se puede observar en la tabla 2 que no hubo diferencia estadísticamente significativa $(p>0,05)$ entre los tratamientos en ninguno de los días de muestreo a pesar de que la caracterización de la fuente de fibra proveniente de cáscara de plátano muestra que posee un alto poder antioxidante, lo cual podría ser el resultado de la oxidación previa del eritorbato de sodio y de los polifenoles presentes en la fuente de fibra, compuestos que al momento de la caracterización de la fuente de fibra presentaron poder antioxidante debido a que solo habían sido sometidos a un tratamiento térmico (secado a $60^{\circ} \mathrm{C}$ ) pero al ser sometido al segundo y tercer tratamiento térmico (1er y 2 do protocolo de cocción de la hamburguesa) podría haberse oxidado una gran parte de estos compuestos, por lo cual ya no tendrían ningún efecto protector sobre la fracción lipídica de la hamburguesa; lo anterior es sustentado en que tanto el ácido eritorbico (producto de disociación de la forma salina eritorbato de sodio en solución acuosa) como los polifenoles son muy susceptibles a la presencia de oxígeno y a las altas temperaturas $[1,28]$.

En cuanto a la degradación proteica, la tabla 3 muestra que esta variable al igual que la oxidación lipídica también presentó aumento de sus valores a través del tiempo con diferencias estadísticamente significativas $(p<0,05)$. Adicionalmente, los valores presentados en la tabla 3 independientemente del tratamiento, son superiores a lo reportado por González, Suárez y Martínez [29] quienes realizaron un monitoreo de jamón de cerdo en el tiempo (42 días) en términos de bases nitrogenadas volátiles evaluando la susceptibilidad de éste para la producción de bases en condiciones de almacenamiento a dos temperaturas, 4 y $8^{\circ} \mathrm{C}$, en las cuales los productos cárnicos presentaron también diferencias estadísticamente significativas a través del tiempo hasta alcanzar 11,2 y 12,6 mg de bases nitrogenadas volátiles/100 g de producto cárnico respectivamente al finalizar el tiempo de estudio. Sin embargo, durante todos los tiempos de muestreo los valores de bases nitrogenadas volátiles de esta investigación se mantuvieron dentro de la categoría de aceptable para el consumo [30] la cual se encuentra entre 20 y $30 \mathrm{mg}$ de bases nitrogenadas volátiles/100 g de producto cárnico. Por otra parte, en los tratamientos con inclusión de fuente de fibra dietaria, la producción de bases nitrogenadas sí presentó diferencias estadísticamente significativas $(p<0,05)$ con respecto al tratamiento control, lo cual indica que a pesar de que no se presentó un efecto

\section{TABLA 2}

Valores de malonaldehído ( $\mu \mathrm{g} / \mathrm{g}$ de hamburguesa) a través del tiempo para los tratamientos con $0 \mathrm{~g}, 5,5 \mathrm{~g}$, y 6,5 g de inclusión de la fuente de fibra dietaria /100 g de hamburguesa.

\begin{tabular}{|c|c|c|c|c|c|}
\hline Tratamientos & día 0 & día 7 & día 14 & día 21 & día 28 \\
\hline $\begin{array}{l}\text { Inclusión de } 0 \mathrm{~g} \text { de fuente } \\
\text { de fibra dietaria/100 g } \\
\text { de hamburguesa }\end{array}$ & $0,11 \pm 0,01^{\mathrm{Aa}}$ & $0,11 \pm 0,001^{\mathrm{Ab}}$ & $0,22 \pm 0,01^{A c}$ & $0,23 \pm 0,01^{A c}$ & $0,22 \pm 0,01^{A c}$ \\
\hline $\begin{array}{l}\text { Inclusión de } 5,5 \mathrm{~g} \text { de fuente } \\
\text { de fibra dietaria/100 g } \\
\text { de hamburguesa }\end{array}$ & $0,11 \pm 0,01^{\mathrm{Aa}}$ & $0,12 \pm 0,01^{\mathrm{Ab}}$ & $0,22 \pm 0,01^{A c}$ & $0,22 \pm 0,01^{A c}$ & $0,23 \pm 0,01^{\mathrm{Ad}}$ \\
\hline $\begin{array}{l}\text { Inclusión de } 6,5 \mathrm{~g} \text { de fuente } \\
\text { de fibra dietaria/100 g } \\
\text { de hamburguesa }\end{array}$ & $0,12 \pm 0,01^{\mathrm{Aa}}$ & $0,12 \pm 0,01^{A b}$ & $0,22 \pm 0,01^{A c}$ & $0,22 \pm 0,01^{A c}$ & $0,23 \pm 0,01^{A c}$ \\
\hline
\end{tabular}


protector sobre la fracción lipídica, si hubo una disminución en la producción de bases nitrogenadas volátiles, lo que podría deberse a pequeños rastros de eritobato de sodio y pequeñas cantidades de polifenoles que lograron permanecer estables a pesar de que en total hubo exposición de estas moléculas a tres tratamientos térmicos.

Por último, los resultados de la composición proximal (tabla 4) obtenida del producto cárnico después de su elaboración permitió comprobar que para los tres tratamientos se cumplió con la normatividad establecida para la formulación de un producto cárnico cocido de categoría Premium acorde con la NTC 1325 [14]. En cuanto a los tratamientos con inclusión de la fuente de fibra dietaria también se cumplió con lo establecido en la Resolución 333 [6] la cual dictamina que para poder rotular un producto como "buena fuente" de fibra dietaria, éste debe contener al menos 2,5 g de fibra dietaria/ porción lo cual correspondería a 10\% del valor de referencia, que en el caso de la fibra dietaria según la misma norma es de $25 \mathrm{~g} /$ día y por tanto los valores para fibra dietaria consignados en la tabla 4 se encuentran acordes a la normatividad.

\section{CONCLUSIONES}

La fuente de fibra obtenida a partir de cáscara de plátano es un recurso que tiene un alto potencial para su utilización en matrices alimenticias procesadas tipo cárnicas ya que los datos obtenidos de la caracterización mostraron que posee altos valores de capacidad antioxidante y fenoles totales los cuales generan protección de la fracción proteica del producto. La adición de la fuente de fibra dietaria obtenida a partir de cáscara de plátano mejora los niveles de fibra dietaria del producto cárnico cocido tipo hamburguesa permitiendo que el producto pueda ser rotulado con el descriptor "buena fuente de fibra" según la normatividad Colombiana.

Los tratamientos con inclusión de la fuente de fibra dietaria $(5,5 \mathrm{~g}$ de fuente de fibra dietaria/100 g de hamburguesa y $6,5 \mathrm{~g}$ de fuente de fibra dietaria/100 g de hamburguesa) no presentaron diferencias entre si en cuanto al efecto que se obtuvo sobre los valores de degradación lipídica y proteica, por lo cual se considera que el tratamiento con inclusión de $6,5 \mathrm{~g}$ de fuente de fibra dietaria/100 g de producto cárnico es el más adecuado puesto que contribuye en mayor medida

\section{TABLA 3}

Valores de bases nitrogenadas volátiles (mg BNV/100 g de hamburguesa) a través del tiempo para los tratamientos con $0 \mathrm{~g}, 5,5 \mathrm{~g}$, y 6,5 g de inclusión de la fuente de fibra dietaria /100 g de hamburguesa.

\begin{tabular}{|c|c|c|c|c|c|}
\hline Tratamientos & día 0 & día 7 & día 14 & día 21 & día 28 \\
\hline $\begin{array}{l}\text { Inclusión de } 0 \mathrm{~g} \text { de fuente } \\
\text { de fibra dietaria/100 g } \\
\text { de hamburguesa }\end{array}$ & $23,49 \pm 0,01^{\mathrm{Aa}}$ & $25,44 \pm 0,82^{\text {Aab }}$ & $21,67 \pm 0,77^{\text {Aac }}$ & $24,43 \pm 1,69 A^{a b c}$ & $24,88 \pm 0,03 A^{a b c}$ \\
\hline $\begin{array}{l}\text { Inclusión de } 5,5 \mathrm{~g} \text { de fuente } \\
\text { de fibra dietaria/100 g } \\
\text { de hamburguesa }\end{array}$ & $18,84 \pm 0,83^{\mathrm{Ba}}$ & $19,82 \pm 0,79^{\mathrm{Ba}}$ & $23,41 \pm 0,08^{A b}$ & $22,11 \pm 0,07^{\mathrm{Bb}}$ & $22,08 \pm 0,06^{\mathrm{Bb}}$ \\
\hline $\begin{array}{l}\text { Inclusión de 6,5 g de fuente } \\
\text { de fibra dietaria/100 g } \\
\text { de hamburguesa }\end{array}$ & $17,98 \pm 0,01^{\mathrm{Ba}}$ & $20,22 \pm 0,76^{\mathrm{Bb}}$ & $22,11 \pm 0,06^{A b}$ & $22,09 \pm 0,03^{\mathrm{Bb}}$ & $22,11 \pm 0,03^{\mathrm{Bb}}$ \\
\hline
\end{tabular}

Letra mayúscula diferente $(A, B, C)$ indica diferencia estadísticamente significativa $(P<0,05)$ en la misma columna según prueba de Tukey.

Letra minúscula diferente $(a, b, c, d, e)$ indica diferencia estadísticamente significativa $(P<0,05)$ en la misma fila según prueba de Tukey.

\section{TABLA 4}

Composición química proximal de hamburguesa con inclusión de $0,5,5$, y 6,5 g de inclusión de fuente de fibra dietaria obtenida a partir de cáscara de plátano /100g de hamburguesa.

\begin{tabular}{|c|c|c|c|c|c|}
\hline Tratamientos & $\begin{array}{l}\text { Proteína cruda } \\
\text { (g/100 g de } \\
\text { hamburguesa) }\end{array}$ & $\begin{array}{l}\text { Extracto etéreo } \\
\text { ( } \mathrm{g} / 100 \mathrm{~g} \text { de } \\
\text { hamburguesa) }\end{array}$ & $\begin{array}{c}\text { Cenizas } \\
\text { (g/100 g de } \\
\text { hamburguesa) }\end{array}$ & $\begin{array}{c}\text { Humedad } \\
\text { (g/100 g de } \\
\text { hamburguesa) }\end{array}$ & $\begin{array}{l}\text { Fibra dietaria } \\
\text { (g/100 g de } \\
\text { hamburguesa) }\end{array}$ \\
\hline $\begin{array}{l}\text { Inclusión de } 0 \mathrm{~g} \text { de fuente } \\
\text { de fibra dietaria/100 g } \\
\text { de hamburguesa }\end{array}$ & 14,79 & 23,43 & 3,10 & 59,04 & 0,0 \\
\hline $\begin{array}{l}\text { Inclusión de 5,5 g de fuente } \\
\text { de fibra dietaria/100 g } \\
\text { de hamburguesa }\end{array}$ & 14,45 & 21,53 & 3,78 & 54,22 & 2,59 \\
\hline $\begin{array}{l}\text { Inclusión de } 6,5 \mathrm{~g} \text { de fuente } \\
\text { de fibra dietaria/100 g } \\
\text { de hamburguesa }\end{array}$ & 14,1 & 22,62 & 3,65 & 52,21 & 2,95 \\
\hline
\end{tabular}


a cubrir el requerimiento diario de fibra dietaria que estipula la normatividad colombiana.

\section{RESUMEN}

Con el objetivo de generar una propuesta de aprovechamiento de los subproductos de la agroindustria del plátano, en esta investigación se caracterizó una fuente de fibra dietaria obtenida a partir de cáscara de plátano (Musa $A A B)$ en términos de fibra dietaria, fenoles totales y capacidad antioxidante; posteriormente se evaluó el efecto de la inclusión de la fuente de fibra dietaria a niveles de $0 \mathrm{~g}, 5,5 \mathrm{~g}$, y 6,5 g de inclusión de la fuente de fibra dietaria $/ 100 \mathrm{~g}$ de producto cárnico tipo hamburguesa (tratamientos) durante un periodo de tiempo de 28 días (con muestreos los días 0, 7, 14, 21 y 28) sobre la degradación lipídica y proteica en términos de producción de malonaldehído por gramo de producto cárnico (hamburguesa) y bases nitrogenadas volátiles por cada 100 g de producto cárnico tipo hamburguesa. Los tratamientos con inclusión de fibra dietaria no tuvieron efecto significativo sobre la degradación lipídica $(p>0,05)$ mientras que en la degradación proteica sí se presentaron diferencias estadísticamente significativas $(p<0,05)$ siendo menores los valores de bases nitrogenadas volátiles obtenidos de los tratamientos con 5,5 g, y 6,5 g de inclusión de la fuente de fibra dietaria /100 g de hamburguesa. Se concluye que la fuente de fibra dietaria obtenida a partir de cáscara de plátano mediante el proceso aplicado, puede utilizarse para aumentar el nivel de fibra dietaria en un producto cárnico tipo hamburguesa y para obtener un efecto protector sobre la fracción proteica del producto cárnico.

Palabras clave: fibra dietaria, capacidad antioxidante, cáscara de plátano, degradación lipídica, degradación proteica.

\section{BIBLIOGRAFÍA}

1. Rong, T., Chemistry and Biochemistry of Dietary Polyphenols. Nutrients 2010; 2: 1231-46.

2. Sekher, A., Chan, T.S., O'Brien, P.J. and Rice, C.A., Flavonoid B-Ring Chemistry and Antioxidant Activity: Fast Reaction Kinetics. Biochemi Biophys Res Commun. 2001; 282(5): 1161-68.

3. Someya, S., Yoshiki, Y. and Okubo, K., Antioxidant compounds from bananas (Musa Cavendish). Food Chem. 2002; 79(3): 351-4.

4. González, R., Lobo, M. and González, M., Antioxidant activity in banana peel extracts: Testing extraction conditions and related bioactive compounds. Food Chem. 2010; 119(3): 1030-9.

5. Happi, T., Andrianaivo, R., Wathelet, B., Tchango, J. and Paquot, M., Effects of the stage of maturation and varieties on the chemical composition of banana and plantain peels. Food Chem 2007; 103(2): 590-600.

6. Ministerio de la Protección Social, Resolución 333 por la cual se establece el reglamento técnico sobre los requisitos de rotulado o etiquetado nutricional que deben cumplir los alimentos envasados para consumo humano. Diario Oficial de Colombia. 2011; (Edición 47.984).

7. Buitrago, A.R., Elaboración de productos horneados suplementados con fibra de maracuyá (Passiflora edulis var.flavicarpa), in Departamento de Quimica, Universidad Nacional de Colombia Sede Bogota: Bogota, Colombia. p. 25. 1997.

8. Son, S.M., Moon, K.D. and Lee, C.Y., Inhibitory effects of various antibrowning agents on apple slices. Food Chem. 2001; 73(1): 23-30.
9. Iyengar, R. and McEvily, A.J., Anti-browning agents: alternatives to the use of sulfites in foods. Trends in Food Science \& Technology. 1992; 3(0): 60-64.

10. AOAC, Official methods of analysis. Total dietary fiber enzymatic-gravimetric (method 985.29), insoluble dietary fiber (method 991.42) Ed. Assn. of Official Analytical Chemists, 16th. 1998.

11. Stratil, P., Klejdus, B. and Kubán, V., Determination of total content of phenolic compounds and their antioxidant activity in vegetables--evaluation of spectrophotometric methods. J Agricul Food Chem. 2006; 54(3): 607-16.

12. Re, R., Pellegrini, N., Proteggente, A., Pannala, A., Yang, M. and Rice, C.A., Antioxidant activity applying an improved $A B T S$ radical cation decolorization assay. Free Radical Biol Med 1999; 26(9-10): 1231-7.

13. Benzie, I.F. and Strain, J.J., The Ferric Reducing Ability of Plasma (FRAP) as a Measure of "Antioxidant Power": The FRAP Assay. Analyt Biochem. 1996; 239: 70 - 6.

14. ICONTEC, Norma Técnica Colombiana Industrias Alimentarias. Productos cárnicos procesados no enlatados. Quinta Edicion ed. NTC 1325. 25. 2008.

15. AOAC, Official Methods of Analysis. Moisture (method 950.46), crude protein (method 935.11), ether extract (method 920.39), ash (method 923.03). Ed. Assn. of Official Analytical Chemists, 17th. 2002.

16. Grigelmo, M. and Martín, B., Characterization of dietary fiber from orange juice extraction. Food Res Internat. 1998; 31(5): 355-61.

17. Abdul, H.A. and Luan, Y.S., Functional properties of dietary fibre prepared from defatted rice bran. Food Chem. 2000; 68(1): 15-9.

18. Vergara, N., Granados, E., Agama, E., Tovar, J., Ruales, J. and Bello, L.A., Fibre concentrate from mango fruit: Characterization, associated antioxidant capacity and application as a bakery product ingredient. LWT - Food Sci Technol. 2007; 40(4): 722-9.

19. Prosky, L., Asp, N.G., Scheweizer, T.F., De Vries, J.W. and Furda, I., Determination of insoluble and soluble and total dietary fibre in foods and food products: Interlaboratory study. J Assoc Official Analyt Chem. 1988; 71: 1017 - 23.

20. Figuerola, F., Hurtado, M.a.L., Estévez, A.M.a., Chiffelle, I. and Asenjo, F., Fibre concentrates from apple pomace and citrus peel as potential fibre sources for food enrichment. Food Chem. 2005; 91(3): 395-401.

21. Codex Alimentarius Commision, Report on the 30th session of the Codex Committee on Nutrition and Foods for Special Dietary Uses., in Appendix II, Codex Alimentarius Commission: Rome. p. 46, 2009.

22. American Dietetic Association, Position of the American Dietetic Association: Health Implications of Dietary Fiber. J Am Diet Assoc. 2008; 108(10): 1716-31.

23. Sulaiman, S., Yusoff, N., Eldeen, I., Seow, E., Sajak, A., Supriatno and Ooi, K., Correlation between total phenolic and mineral contents with antioxidant activity of eight Malaysian bananas (Musa sp.). J Food Composition Anal. 2011; 24(1): 1-10.

24. Babbar, N., Oberoi, H., Uppal, D. and Patil, R., Total phenolic content and antioxidant capacity of extracts obtained from six important fruit residues. Food Res Internat. 2011; 44(1): 391-6.

25. Kaur, C. and Kapoor, H.C., Antioxidants in fruits and vegetables - the millennium's health. Internat J Food SCi Technol. 2001; 36(7): 703-25. 
26. Fernández, G., Fernández, L.J., Sayas, B.E., Sendra, E. and Pérez-Alvarez, J.A., Effect of Storage Conditions on Quality Characteristics of Bologna Sausages Made with Citrus Fiber. J Food Sci. 2003; 68(2): 710-4.

27. Sáyago, S.G., Brenes, A. and Goñi, I., Effect of grape antioxidant dietary fiber on the lipid oxidation of raw and cooked chicken hamburgers. LWT - Food Sci Technol. 2009; 42(5): 971-6.

28. Morales, P., Vegetales Silvestres de uso Alimentario: Determinación de Compuestos Bioactivos y Valoración de la Capacidad Antioxidante, in Departamento de Nutrición y
Bromatología, Facultad de Farmacia, Universidad Complutence de Madrid: Madrid, España. p. 359, 2011.

29. González, M., Suárez, H. and Martínez, O., Influencia del proceso de cocción y temperatura de almacenamiento sobre las características fisicoquímicas, microbiológicas y sensoriales del jamón de cerdo. Rev Colombiana Ciencias Pecuarias. 2010; 23: 336-8.

30. SENASA, Decreto 29210. Reglamento Técnico, Límites Máximos Permitidos para Residuos Tóxicos y Recuentos Microbiológicos para los Productos Alimenticios. Servicio Nacional de Salud Animal - SENASA, Costa Rica. 2003. 